Eesti Arheoloogiaajakiri, 2004, 8, 1, 84-88

\title{
ETNOGENEESIST INTERDISTSIPLINAARSE KOOSTÖÖ VALGUSES \\ HETKEOLUKORRA PEEGELDUS ARHEOLOOGIA JA KEELETEADUSE KEVADKOOLI TAUSTAL
}

\author{
Kristiina Johanson ja Marge Konsa \\ Tartu Ülikooli arheoloogia õppetool, Lossi 3, 50090 Tartu, Eesti; Kristiina.Johanson@ut.ee; \\ Marge.Konsa@ut.ee \\ Muutused ja kronoloogiad materiaalses kultuuris ja keeles. Arheoloogia ja keeleteaduse kevadkool, \\ 6.-7.03.2004, Ähijärve, Eesti
}

Eesti arheoloogia ja ajaloolise keeleteaduse suurimaks "ühisprojektiks" nende teaduste ajaloos võib pidada 1950. aastatel loodud eesti etnogeneesi teooriat. Eesti põhiseaduses leidis see kajastust kui eestlaste õigustus oma maale, tuginedes 5000 aasta vanustele soome-ugri juurtele. Kooliõpikutes illustreerivad teooriat pildid Valma kammkeraamika ja Ardu nöörkeraamika kultuuri mehest, kelles on vastandatud soome-ugri ja indoeuroopa päritolu, mongoliidsus ja europiidsus. Nimetatud neoliitilise idast tulemise idee aluseks oli keelesugulus meist ida pool elavate rahvastega, mis asetas soomeugrilaste algkodu Volga-Kaama jõgikonda, ning toetajaks kultuuriajalooline seisukoht arheoloogilise kultuuri, keelerühma ja etnose võrdsustamisest, mis tingis kammkeraamika kultuuri samastamise hilisemate läänemeresoomlastega (Kriiska 2003, 50). Kuigi viimasel kümnendil on nii eesti keele kui ka Eesti kaugeima mineviku arheoloogiline uurimine arenenud kiiresti ning tekkinud on uued, varasemast täiesti erinevat lähenemisviisi ja tulemusi esitavad teooriad, on teema sisuline arutelu jäänud kesiseks. See on viinud teadustulemuste väärkasutuseni, arusaamatusteni, skepsiseni etnogeneesi uurimise suhtes üldse ning kokkuvõttes suurendanud lõhet ühest küljest nii rahvusteaduste enesemääratluse ja avaliku arvamuse vahel rahvusteaduste eesmärkidest kui ka teaduste ettekujutuste vahel "teises" teaduses toimuvast.

Kas ja kuidas on võimalik uurida eestlaste etnilist kujunemist? Kas materiaalses kultuuris nähtavad muutused ja arengud ühtivad keele muutuste ja kronoloogiaga? Need olid küsimused, mille arutlemiseks viidi 6.-7. märtsil 2004. aastal Karulas Ähijärvel läbi arheoloogide ja keeleteadlaste kevadkool. Foorumi esmaülesandeks ei olnud siiski mitte konkreetsete vastuste ja lahendite leidmine nimetatud probleemidele, vaid oma vaadete, meetodite ja uurimisülesannete tutvustamine teise, suhteliselt võõra distsipliini esindajatele ning mitteametlikus vormis mõtete vahetamine kahte teadusharu ühendavatel teemadel. 


\section{Etnogeneesi küsimuse aktuaalsusest tänapäeval}

Keeleteadlaste ja arheoloogide ühises diskussiooniringis tõdeti taas, et nõukogude ajal aktuaalseks saanud etnogeneesi teooria, mis eksponeeris 20. sajandi keskel välja töötatud põhipostulaate (teadus)kirjanduses endisel kujul veel 1990. aastateni, ei sobi uute teadustulemuste põhjal enam tänapäevaste mõttemallidega. Keelepuu mudelile lähtekohaks olevale uurali või soome-ugri algkeelele vastavaid kultuure, populatsioone ega nende järgi oletatavaid rändeid ei ole arheoloogidel õnnestunud välja selgitada (Tõnisson 1996, 747). Materiaalses kultuuris toimunud muutuste seletamine migratsiooni abil on vaid üks võimalustest, mida pealegi pole arheoloogiliste vahenditega võimalik tõestada (Lang 1998). Ka geneetikute andmed ei toeta ühtki suuremat migratsiooni Eesti alale pärast algsete esivanemate saabumist (Künnap 1998).

1990. aastatel sai üheks alternatiivseks hüpoteesiks keelte ja rahvaste kujunemiskäigu rekonstrueerimisel keeleteadlaste Kalevi Wiiki ja Ago Künnapi esitatud nn kontaktiteooria. Keeleteaduse, arheoloogia, antropoloogia ja geneetika andmeid ühendada üritava seisukoha peamiseks selgelt sõnastatud avalduseks on distantseerumine keelte sugupuu mudelist ning migratsionistlikust lähtepunktist ja põhialuseks on veendumus, et muutused keeltes ja kultuurides toimuvad esmajoones nende omavaheliste kontaktide ja segunemiste tagajärjel, kehtiva lingua franca ehk "rahvusvahelise keele" kaudu (Wiik 2001, 394). Ühe algkodu asemel kitsal territooriumil Euroopa-Aasia vahemail näeb kontaktiteooria soomeugrilaste esialgse asustuspiirkonnana üht kolmest Euroopas asunud refuugiumialast. Nii toimisid vastavalt ibeeri, balkani ja ukraina refuugiumides räägitavad baski, indoeuroopa ja soome-ugri (uurali) keeled neis piirkondades lingua franca põhimõttel, kusjuures uurali rass, resp algkeel, kattis Euroopa hõivamise järel kogu PõhjaEuroopa jääserva lähedase ala Suurbritanniast Komimaani (nt Wiik 1999, 299 jj). Wiiki järgi jagunesid geneetiliselt erinevad rahvarühmad jääajajärgses Euroopas just toimetulekuskeemide erinevuste põhjal kahe laia keelevööndi vahel: nii oli 9000 aasta eest põhjas valitsevaks suurulukiküttide uuralipärane keelevorm (ehk uurali algkeel) ning lõunas väikeulukiküttide indoeuroopapärane keelevorm (ehk indoeuroopa algkeel) (Wiik 1999, 292-293). Ka keelevahetused on Wiiki ja Künnapi järgi tingitud eelkõige majanduslikest muutustest: kui Lõuna-Euroopa soodsas kliimas kujunenud põllumajandus hakkas tänu kliima mahenemisele põhja poole levima, võttis varem uurali algkeelt rääkinud rahvas koos uue põlluharijate eluviisiga üle ka prestiižsema indoeuroopa keele (Wiik 2001, 394).

Mainitud teooria on tekitanud üsna palju vaidlusi ning kevadkoolis selgus, et ka eesti keeleteadlastel pole mudeli suhtes sugugi veendunud ja üheselt mõistetavat seisukohta. Üsna paljud noored teadlased pole Künnapi ja Wiikiga nõus: väidetakse, et lingvo-arheo-geneetilist keeleteadust ei ole teadusmaastikule vaja ning ehkki koostööd on tarvis, ei ole kõiki "tööriistu" teistest valdkondadest alati võimalik kasutada. Lingvistid tegelevad keeltega ning vajavad selle uurimiseks omi tööriistu. "Me [keeleteadlased] ei leia kõiki puuduvaid vastuseid teistest valdkondadest, mõnikord ehk uusi ideid, kui üldse neidki!" (Siegl 2003). Teooriat on nimetatud ka uueks fantaasiarikkaks üleöö üles joonistatud soome-ugri keelte tekkeloo pildiks ning "nüüdisaja interdistsiplinaarsuse (eklektitsismi) mõtteks perfektsel kujul" (Hasselblatt 1999). Arheoloogide jaoks pakub kontaktiteooria küll uudset lähenemisviisi, ent kahjuks lähtub seisukoht sarnaselt keelepuu mudelile endist viisi kultuuriajaloolisest arheoloogiliste kultuuride ja keelerühmade võrdsustamisest.

Teine probleem, mis mainitud küsimusega haakub, on algkeele ja selle kodu otsimise mõttekus üldse. Keeleteadlased on oma distsipliini algusaegadest peale üritanud algkeeli rekonstrueerida. Enamik ajaloolise lingvistikaga tegelejaid usub, et geneetilise suguluse põhilisim ja parim tõestus on ühte keeleperekonda kuuluvate keelte ühise esivanema ehk algupärase keele rekonstruktsioon (Campbell 1998, 108). Levinud seisukoha järgi on iga esikeel (protokeel) olnud kunagi tõeline ja reaalselt eksisteerinud (nt Campbell 1998, 109) ning võrdleva-ajaloolise lingvistika ülesandena on nähtud selle keeleni jõudmist - samm-sammult olevikust minevikku tagasiminemine, et kõige usutavamate keelemuutuste väljaselgitamise abil tuletada võimalikke eksisteerinud keelevorme ning 
viimaste kaudu jõuda alg- ehk protokeeleni (Hock \& Joseph 1996, 456). Ajaloolise keeleteaduse ideaal- või algkeele otsingute ekvivalendiks arheoloogias võiks olla algkultuuri kui mingil ajahetkel teatud piirkonnas eksisteerinud esialgse rahvarühma väljaselgitamine, kellest kõik edasine on alguse saanud. Selline taandamatu tasandi saavutamine on paljude arheoloogide jaoks jäänud uurimistöö kütkestavaks, ent siiski lõpuni kättesaamatuks eesmärgiks.

Kevadkoolis selgus, et senikehtinud etnogeneesi teooriale "õigema" järeltulija põhjalik väljatöötamine ning uue teadustulemuse "inimesteni viimine" ei ole õigupoolest atraktiivne kummagi teadusharu jaoks. Alg- ehk ideaalkeel, aga ka algkultuur on hüpoteetilised mõisted ning ei ole enam reaalsel kujul kättesaadavad, seega on ka kõik rekonstruktsioonid suvalised, ehk koguni meelevaldsed, tuginedes näiteks algkeele puhul keerulisele häälikumuutuste reeglistikule ning mõnekümne ühise sõna olemasolule tütarkeeltes (Meri 1997). Sarnaselt keeleteaduses puhuvatele tuultele, kus esialgse keele otsingud ei ole enam aktuaalsed, ei püüta ka arheoloogias enam tänapäeva rahvaste juuri otsida. 1950. aastail postuleeritud hüpoteesile 5000 aastat tagasi Eesti alale jõudnud soome-ugri algupära kandvast kammkeraamika kultuuri rahvast, meie esivanematest, on välja pakutud ka alternatiive, mis aga ei ole saavutanud ega taotlenudki samaväärset refleksiooni ühiskonnas. Ühe näitena võiks siinkohal mainida käsitlust "eestlaste" 11 000-aastasest ajaloost omal territooriumil, või pigem nende kõikide ajaloost, kes siin alates viimase jää minekust on elanud ja läbi arengupidevuse muutunud ning keda me iseenda enesemääratlusele tuginedes eestlasteks nimetame (Kriiska 2003, 52).

Etnogeneesi ning sellega liituva algkeele/algkodu küsimus ei ole enam ligitõmbav ka ehk minevikust õpitud kogemuse taustal: nimelt on igasugune "ideaalne" (resp alg-, proto-, esi-) rahvusküsimusena poliitiliselt kergesti manipuleeritav ja taolisi märksõnu sisaldavale teemale asumine väljuks reeglina teaduse kontrolli alt.

\section{Arheoloogia ja keeleteaduse paralleelsus ja lõikumine}

Muinasteadlaste jaoks traditsioonilisteks peetud millal- ja kus-küsimuste kõrval on arheoloogid pikalt tegelnud ka miks- ja kuidas-probleemidega. Viimased pole keeleteaduses sugugi võõrad ajalooline lingvistika tunneb samamoodi huvi, miks keeled muutuvad, ning pöörab samas tähelepanu teooriatele, mis aitaksid neid muutusi seletada (Campbell 1998, 6). Kus ja millal, miks ja kuidas muutused toimuvad? Missugust rolli mängivad muutustes laenud, millist kultuurisisesed impulsid? Arheolooge ja keeleteadlasi liidab huvi selle vastu, kuidas on üleüldse võimalik neile küsimustele vastata. Millised vahendid selleks on ja kuivõrd need meediumid end õigustavad?

Lähtuvalt oma uurimisobjektist tajuvad ning seletavad arheoloogid ja keele ajaloo uurijad mainitud muutusi erinevalt. Ent iga viljakust taotleva interdistsiplinaarse koostöö esmaaluseks on teise teaduse eesmärkide ja meetodite mõistmine ning tunnustamine. Arheoloogid on väga sageli pöördunud keeleteaduse poole, leidmaks lingvistilist kinnitust mingitele nähtustele või tõmbamaks paralleele näiteks arheoloogilises materjalis nähtavate regionaalsete erisuste ja keeles esinevate murdeerinevuste vahel (nt Jaanits jt 1982; Laul 2001), samas ollakse sunnitud tõdema, et tegelikult puudub igasugune kehtiv ja arvestatav metodoloogia, ühendamaks keelte ajaloolisest uurimisest omandatud ainest arheoloogilise materjaliga. Colin Renfrew' sõnastuses seisneb probleem selles, et kuigi varasest (kirja-eelsest) perioodist pärit arheoloogiline materjal ei ütle meile mitte midagi otseselt selle kohta, milliseid keeli räägiti, on minevikujääned ehk materiaalne kultuur siiski paigutatav kindlasse kronoloogilisse raamistikku. Meil on võimalik öelda, millal mingid asjad on tehtud. Seevastu ajalooline keeleteadus võib teatava usutavuseni konstrueerida varast keelevormi hilisematele toetudes, ent samas ei ole mingit viisi selle paigutamiseks kindlasse ajavahemikku (Renfrew 1988, 285). Kevadkoolis vastavat temaatikat käsitlenud keeleuurija Florian Siegl mainis eeltooduga nõustudes, et lingvistide uurimisobjektiks on ajaloolised muutused keeles ja põhjuse-tagajärje seoste analüüs, kuid seda siiski ainult suhtelisel skaalal. Sündmused arheoloogias ja keeles ei ole 
kattuvad nähtused, need puudutavad ühiskonna erinevaid tahke ning nende ajendid ja tagamaad ei ühildu, seetõttu ei ole ka eri teadustes rakendatavad kronoloogiad omavahel nii hõlpsasti ühildatavad.

Ometi on vähemalt mõnikord keelemuutuste ja laenude taga tõepoolest ajaliselt jälgitav migratsioon. Näiteks demonstreeris kevadkoolis esinenud Meeli Sedrik oma ettekandes rootsi laenudest Hiiumaa murrakutes, et teatavatel juhtudel on keelemuutusi (uudissõnad, mõisted, süntaks) võimalik seostada ajalooliselt dokumenteeritud sündmuste ja nähtustega või keskkonna muutustega. Usutavasti ei oleks Hiiumaa murrakutes nii palju rootsi laene ilma rootslaste sisserändeta Lääne-Eesti rannikualale.

Kõige laiemas mõttes ühendab arheoloogide ja ajalooliste keeleteadlaste uurimissuundi inimene, tema kohalolek minevikus, ent ühe liituva meediumina ei ole konkreetne paik sugugi vähem oluline. Kohanimed tähistavad kohti maapinnal ning ühtlasi liigendavad maastikku vastavalt inimeste vajadusele, lisaks on kohale nime andmine inimese viis maailma "hingestada" (Päll 2002, 227). Kui keeleuurijaid huvitab kohanimi ning selle panemise loogika, siis arheolooge selle taga peituv tähendus, paiga iseloom. Just sellelt maailma hingestamise loogika tasandilt lähtub reaalselt eksisteeriv koostöö arheoloogia ja ajaloolise lingvistika vahel, mille ühe näitena võis kevadkoolis kuulata Evar Saare ettekannet mallinimedest. Näiteks saab linnamägi oma nime tihti mitte sellel tõepoolest asuva muistise järgi, vaid pigem oma linnamäge meenutava morfoloogilise kuju ning sellelt pinnalt kujunevate assotsiatsioonide põhjal. Seevastu kalmemäe puhul ei ole künka kujul sellele toponüümi andmisel olulist tähtsust, pigem sai koht nime just seal asuva matmispaiga järgi.

\section{Kokkuvõte}

Arheoloogiateaduses on interdistsiplinaarsuse vajalikkus kaheldamatu. Asetades inimese uurimistöö keskpunkti, on paratamatu, et üks teadusharu ei suuda hõlmata kogu elu selle aspektide rikkuses, vaid peab arvestama ka naaberteaduste tulemustega. Seevastu keeleteaduse tänased uurimisprobleemid on lingvistika töömeetodite ja vahenditega suures ulatuses kaetavad. Kunagised laiahaardelised ja ülevad teemad, nagu etnogeneesi uurimine, esivanemate algkodu ja algkeele otsingud, ei ole enam moes.

Arheoloogia ja võrdleva-ajaloolise keeleteaduse uurimisobjektid ning -traditsioonid on oma olemuselt üksteisest küll suhteliselt kaugel, ent metodoloogiliselt ei erinegi need kaks teadusharu nii kardinaalselt. Võrdleval meetodil on ka muinasteaduses oma täiesti vajalik ja asendamatu roll. Enamik arheolooge kasutab oma töös esemelises materjalis süsteemi loomiseks võrdlemist, ilma milleta on tõlgendamisprotsessi ka üsna raske ette kujutada ja läbi viia. Teiseks sarnaseks teadusmetodoloogiliseks jooneks kahe distsipliini vahel on püüd jõuda teatud minevikuaspektide (re)konstruktsioonini. Selles tegevuses on aga mõlema teadusharu jaoks muutunud protsessi taaskujutamine olulisemaks kui ühtse lõpptulemuse - rahvusteaduste abiga esivanemate juurteni jõudmine - taotlus. Protsessid, mida keeleteadus ja arheoloogia rekonstrueerivad, on erinevad. Kuna nii ajaloolised lingvistid kui ka arheoloogid on võimelised kas siis keeles või ühiskonnas toimuvaid muudatusi adekvaatselt vaatlema enamasti vaid suhtelisel skaalal, on relatiivsuse küsimus üheks olulisemaks probleemiks kahe teadusharu tulemuste lõimumisel.

Ajaloolise keeleteaduse ja arheoloogia koostöökatsed ei seisne niivõrd metodoloogiliste sarnasuste otsimises, ehkki ka see on vajalik ja huvitav, pigem püütakse leida konkreetseid ühiseid teemasid, sarnaseid probleeme, mõlemale poolele ühtmoodi aktuaalseid küsimusi. Ka praeguseks ümberhindamist vajavad seisukohad on olnud ühiseid valdkondi puudutava teadustöö põhjendatud ja orgaaniline tulemus. Niisama loomulikult kaotavad ka hetkel aktsepteeritud hinnangud ühel järgmisel ajahetkel oma aktuaalsuse. Sellist seisukohtade kujundamist, nendes kahtlemist, nende tõestada püüdmist, ümberlükkamist ja taas uute loomist nimetame teaduse arenemiseks, mis ühe potentsiaalina leiab väljundi läbi koostöö. 


\section{Kasutatud kirjandus}

Campbell, L. 1998. Historical linguistics. An introduction. Edinburgh.

Hasselblatt, C. 1999. Eesti keelt kõneldi ka Mount Everestil. - Eesti Päevaleht, 08.12.

Hock. H. H. \& Joseph, B. D. 1996. Language History. Language Change and Language Relationship. An Introduction to Historical and Comparative Linguistics. Berlin; New York.

Jaanits, L., Laul, S., Lõugas, V. \& Tõnisson, E. 1982. Eesti esiajalugu. Tallinn.

Kriiska, A. 2003. Kas nad olid eestlased? - Lehed ja tähed. Looduse ja teaduse aastaraamat 2003, 44-52.

Künnap, A. 1998. Keelepuud pole tegelikult vaja. - Keel ja Kirjandus, 6, 427-428.

Lang, V. 1998. Some aspects of the Corded Ware Culture east of the Baltic Sea. - The Roots of Peoples and Languages of Northern Eurasia. Turku, 84-104.

Laul, S. 2001. Rauaaja kultuuri kujunemine Eesti kaguosas (500 e.Kr. - 500 p.Kr.). (MT, 9. Õpetatud Eesti Seltsi Kirjad, 7.) Tallinn.

Meri, M. 1997. Tormid keelepuu ümber. - Eesti Ekspress, 07.03.

Päll, P. 2002. Eesti kohanimed. - Eesti murded ja kohanimed. Tallinn, 223-297.

Renfrew, C. 1988. Archaeology and Language: the Puzzle of Indo-European Origins. New York.

Siegl, F. 2003. Lingvo-arheo-geneetiliselt eurooplaste algupärast - vastus Ago Künnapile ja Kalevi Wiikile. Listi ugrimugri@lists.ut.ee arhiiv, 15.01.2003.

Tõnisson, E. 1996. Mõned mõtted keelepuu mudelist ja kontaktiteooriast. - Keel ja Kirjandus, 11, 745-748.

Wiik, K. 1999. North-European populations and languages. - Indo-European-Uralic-Siberian Linguistic and Cultural Contacts. Fenno-Ugristica 22. Tartu, 292-301.

Wiik, K. 2001. On the interactions between the Uralic and Indo-European peoples and languages through lingua francas. - Congressus nonus internationalis fenno-ugristarum, 6. Tartu, 391-408. 